cose, fructose, sucrose, maltose, maltotriose, glucose6-phosphate and fructose-1,6-diphosphate.

For the sugary waxy and sugary high-amylose varieties of maize, slices were cut from kernels 13-14 days after pollination; these did not contain any starch before incubation. After incubation with 1 per cent glucose-1-phosphate at room temperature for $3 \mathrm{hr}$. the slices of both varieties showed the presence of generally distributed unorganized polysaccharides that stained red with iodine, but no granules whatever. After 15 and 24 hr., slices of both varieties still contained amorphous polysaccharides that stained red, but also small starch granules all of which stained blue with iodine. Glucose, sucrose, maltotriose and glucose-6-phosphate were again ineffective in the formation of the granules. Oxygen likewise had no effect on their formation.

It is clear from these results that the endosperm of waxy maize has the ability to form amylose from glucose-1-phosphate by a reaction resembling that of phosphorylase, even though no amylose is detectable in the normally growing plant. The most logical explanation seems to be that the waxy variety growing under natural conditions may have some device which effects complete conversion of amylose to amylupectin ${ }^{4}$, whereas in the other varieties tested the mechanism is fur less efficient. Why this mechanism does not function under the laboratory conditions here described is not yet apparent.

The kindness of Dr. H. H. Kramer of Purdue University in furnishing samples of high-amylose maize for this study is most gratefully acknowledged.

This work was supported in part by a grant from the Corn Industries Research Foundation.

\section{Hidetsugu FuWA*}

Biochemistry Department, Purdue University, Lafayette, Indiana. Oct. 31 .

* Present address: Department of Agricultural Chemistry, Nagoya University, Anjo, Aicli, Japan.

1 Duvick, D. D., Bot. Gaz., 115, 82 (1953).

Hori, S., Bot. Mag., 67, 228 (1954).

- Kramer, H. H., Whistler, R. L., and Anderson, E. C., Agron. J., 48, $170(1956)$

- Fuwa, H., Fed. Proc., 15, 258 (1956).

\section{Corticium solani-an Orchid Endophyte}

Corticium solani (Prill. and Delacr.) Bourd and Galz, the soil-inhabiting basidiomycete which attacks a wide range of hosts, has boen isolated repeatedly by me in sterile mycelial form (Rhizoctonia solani) from the roots of the marsh orchid, Orchis purpurella T. and T. A. Steph. Germination tests with the soed of the orchid show that the mycelium of $R$. solani, so isolated, acts as a symbiont stimulating the growth of the embryos. Typical pelotons form within the orchid cells, and later digestion of the hyphæ takes place. Thus the fungus conforms to the normal conditions of an orchid endophyte.

Parasitic forms of this fungus isolated from diseased crop plants also proved acceptable symbionts. In germination tests the following isolates stimulated the growth of Orchis purpurello seed: C. salani from wheat straw (the Commonwealth Mycological Institute No. 39,933), $R$. solani from cauliflower (received from A. Channon, National Vegetable Research Station, Wellesbourne), and $R$. solani from tomato. On the other hand, a form isolated from potato did not enter the embryo, so that no growth-stimulation took place. Those tests prove that forms of the parasitic fungus $C$. solani can act as endophytes of the orchid $O$. purpurella, and it is of interest to note that last summer a plant of o. purpurella was found bearing the collar-like fruitbody of a corticium on the stem at ground-level. This condition is familiar in the case of potatoes attacked by the fungus but has never before been recorded on an orchid. The fruit-body was more tenuous than that found on potato and unfortunately was incom. pletely developed, but measurements of hyphæ and of young basidia are comparable with those on potato at a similar stage of development. An extensive search of other $O$. purpurella plants failed to reveal another plant bearing the fruit-body.

While Rhizoctonia spp. have been isolated repeatedly from terrestrial orchids, none of these, so far as I know, has been linked with a known parasitic species, and on no previous occasion has the corticium stage been recorded occurring naturally on an orchid stern.

A further interest lies in the light this finding throws on the soil ecology of orchid endophytes. These are generally classified with other mycorrhizal fungi as 'root-inhabiting' forms with a limited distribution in the soil ${ }^{1}$. On the other hand, $C$. solani is known to be widely distributed in the soil2,3 and is therefore grouped with the saprophytic sugar fungi as 'soil-inhabiting'. Now that it is known that $C$. solani is a commonly occurring endophyte of O. purpurella, it may be found that other orchid endophytes also fall into the latter category.

Department of Botany,
University of Aberdeen. Oct. 30.

1 Garrett, S. D., New Phytol., 50, 149 (1951).

\&lair, I. D., Ann. App. Biol., 30, 118 (1943).

'Chesters, C. G., Trans. Brit. Mycol. Soc., 32, 197 (1948).

\section{G. DownIE}

\section{Mass Isolation of Viable Wheat Embryos}

Commerclal wheat germ has been a material of choice for biochemical studies ever since its use in the isolation of cytochrome $c$ and cytochrome oxidase ${ }^{1}$. For purposes of physiological research, however, the commercial product has a serious limitation, namely, its non-viability. Samples of commercial material were tested for viability by sprinkling the germ on agar plates, or on filter paper moistened with glucose solution. Less than $0 \cdot 5$ per cent of the embryo-like particles showed signs of incipient germination, and none showed development of the cotyledon. Hand isolations of individual wheat embryos have been reported. Such embryos were used, for example, in mapping the intracellular distribution of hexokinase ${ }^{2}$. Hand picking, however, is a tedious and timeconsuming process, and we therefore undertook to find a convenient means of preparing laboratory quantities of viable material. As a result, a simple procedure for isolating wheat embryos in relatively large amounts has been developed. One operator can prepare 200-250 gm. in a day. Chinook, a spring wheat, was found to be the most suitable of the several varieties tested.

About $250 \mathrm{gm}$. of wheat is mixed with $150 \mathrm{ml}$. of $\frac{1}{2}$-in. lumps of 'dry ice' and after a few minutes the whole is ground for 20 sec. in a quart-size aluminium. 